\title{
EDITORIAL
}

\section{Subspecialization in radiology - Is it time to hatch out of the cocoon?}

\author{
Chander Mohan, SM \\ Director, Interventional Radiology, BLK Superspecialty Hospital, New Delhi, India. \\ E-mail: brigcmohan@gmail.com
}

Medicine for long has been evolving into the realm of subspecialization with specialists dedicated to particular organ system, or nowadays even specific organ, are coming up. Day in and day out we are hearing of new specialties being introduced. From general surgeons to gastrointestinal surgeons to hepatobiliary transplant surgeon, the modern-day surgeon has evolved to be more and more specialized. Even in specialized fields like oncosurgery, we have subspecialists who are further specializing in surgeries of a particular organ system. Similar trend has been seen in medical specialties too where even patients are increasingly wanting to be seen by a subspecialist like a gastroenterologist rather than a general physician. Even the specialty of pediatrics has been split into subspecialties by organ systems.

While medical and surgical specialties have taken the lead in this, radiology has largely resisted this temptation of evolving the general radiology based practice into subspecialty radiology. Gone are the days where cross-sectional imaging was considered the subspecialization with radiologists choosing to specialize in computed tomography (CT) and magnetic resonance (MR) versus those practicing ultrasound and conventional radiology. Across the western world, the subspecialty evolution has moved into organ systems where the radiologist chooses the organ system rather than the modality. For example, a person specializing in musculoskeletal (MSK) radiology needs to be reporting X-rays, performing MSK ultrasounds, CT, MR, and arthrographies and should be able to do basic MSK interventions. Akin is the situation of someone specializing in a specialty like breast where he/she is expected to be able to handle the entire gamut from mammograms, breast ultrasound, and MR mammography to tomosynthesis and breast interventions. This organ-system-based specialization is the direction which is gaining acceptance worldwide.

In our country, the scenario has been different with most radiologists preferring to be general radiologists. The biggest reason for this has to be the crunch of radiologists in the country. You cannot have subspecialists without an adequate number of general radiologists. Even in metro cities, there still exists a shortage of adequate number of general radiologists. The situation is even grave for smaller cities where finding a general radiologist is tough let alone a subspecialist. It is beyond doubt that we need a big pool of general radiologists who are needed to support the healthcare system because lot of times we are performing imaging studies for screening purposes without being able to delaminate to a particular organ system. Also with the vastly skewed demand and supply ratio of radiologists, it is practically impossible to have radiologists dedicated to one particular subspecialty which could compound the already existing shortage of radiologists.

On the other hand, the time has come to reaffirm the relevance of our specialty in medicine which has rapidly diversified into many subspecialties. Our highly-specialized physician and surgeon colleagues are increasingly demanding more specialized interpretation of imaging like the neurologist or neurosurgeon of today wants to be talking sulci and gyri along with functional areas rather than lobes of the brain. This has led to some frustration in our physician colleagues, some of whom have actually started to interpret their specialty imaging themselves like the cardiologists and orthpedicians. It is prudent that we should start evolving our specialty into subspecialty based practice.

For sure the need of the hour is the "Hybrid Imager" where each radiologist has subspecialty training but continues to divide his/her time in the subspecialty as well as general imaging. We need general radiologists to interpret

This is an open access article distributed under the terms of the Creative Commons Attribution-NonCommercial-ShareAlike 3.0 License, which allows others to remix, tweak, and build upon the work non-commercially, as long as the author is credited and the new creations are licensed under the identical terms.

\begin{tabular}{|c|c|}
\hline \multicolumn{2}{|c|}{ Access this article online } \\
\hline Quick Response Code: & \\
\hline \multirow{2}{*}{ 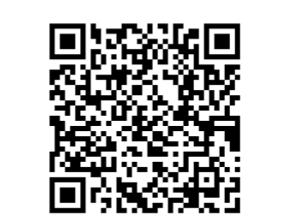 } & $\begin{array}{l}\text { Website: } \\
\text { www.ijri.org }\end{array}$ \\
\hline & $\begin{array}{l}\text { DOI: } \\
\text { 10.4103/ijri.IJRI_345_17 }\end{array}$ \\
\hline
\end{tabular}

Cite this article as: Mohan C. Subspecialization in radiology - Is it time to hatch out of the cocoon? Indian J Radiol Imaging 2017;27:261-2. 
screening and general studies, but we need a backup of the subspecialist radiologists when the specific clinical questions come from our subspecialized colleagues.

If we analyze the flag-bearers of our specialty over the years have not pushed well enough for subspecialization. While medical and surgical specialties have a subspecialist for almost all conceivable fields with recognized and accredited superspecialization courses, for radiology the options are very far and few without standardization. We can literally count on hands the number of institutes running superspecialty courses in radiology like DM. Most of the subspecialization is restricted to fellowships without accreditation which are mostly run by specific institutes without any central accreditation. While the number of self-acclaimed subspecialists based on experience alone is rapidly dwindling in medical and surgical specialties, this trend is rampant in radiology where the need for a structured formal training has been substituted for long by work experience. Ideally speaking any MBBS graduate is licensed to do surgeries but we still have postgraduation in surgery. The same concept conversely applies to radiology where the general radiologist is practicing a broad specialty which has so much information that it is impossible to be mastered by a single person. While other specialties have recognized this need for developing excellence and competency, radiology has been lackadaisical in its approach which needs to be rapidly addressed.

The first and foremost has to be the training program which has to be standardized with compulsory entry and exit examinations. While we have got DM in radiology in very few specialties, they are grossly outnumbered by the $\mathrm{DM} / \mathrm{MCh} / \mathrm{DNB}-\mathrm{SS}$ seats in clinical specialties. The pace of adding more subspecialty seats has been a painstakingly slow process. Consequently, we are experiencing a significant brain drain where young radiologists looking to develop subspecialty competence are left with not many options but to go abroad and do the recognized fellowships where often they end up settling abroad.

At this crucial juncture, National Board of Examinations (NBE) has taken an initiative of introducing standardized DNB-SS and FNB courses in radiology. Recent notification by NBE has initiated subspecialization courses in DNB Endovascular and Interventional Radiology and FNB Breast Imaging. This is a step that needs to be welcomed and embraced. More and more courses as well as seats need to be added. Like every specialty, we need to evolve into subspecialties. If anybody has an apprehension that evolving into subspecialty will weed out the general radiologist, we have the example of general medicine and surgery which also have continued to flourish despite the development of subspecialties.

Like every seed that is sown needs nutrition and protection, making only the courses and seats available will not solve the purpose. These days in our country, it is hard to find befitting jobs for subspecialist radiologists. The government as well as the radiology bodies need to work together to create subspecialty departments with the requisite number of posts to absorb the subspecialist radiologists who will emerge out of these courses. Unless and until we have the subspecialists in requisite numbers we will never be able to gain footing for them, be it in jobs or in the eyes of the private employers as well as the general public. Further, the subspecialist radiologist should not refrain from being the "hybrid imager" that the current situation demands. But first and foremost, it is our attitude that needs to change and we need to accept that anything that does not evolve will eventually not last the test of time and will ultimately be phased out. Subspecialty is not a choice but a need. Perhaps it is the time for us to hatch out of our cocoons into more evolved subspecialists. 